may not therefore be suitable for a trainee intending to work in Africa, although psychotherapists and counsellors involved in general psychiatry or primary care have a lot to teach.

Community psychiatry will have most to offer if the service is not biased towards neurosis. Rehabilitation psychiatry has a surprisingly limited place in the current climate of shortage of staff and facilities. Occupational therapy, work therapy, and retraining may be almost non-existent and training in these areas be inappropriate for some trainees.

Alcohol dependency is a major problem in some countries, both directly and through its effect on psychosis. An attachment to an alcohol service is likely to provide a trainee with many relevant skills.

\section{Teaching}

Most of the basic teaching given on Membership courses is likely to be of relevance to a trainee returning to one of the three countries considered, but they will also need special skills relevant to service development. We have concentrated on the organisation, implementation and evaluation of services on our courses in Manchester but have possibly paid inadequate attention to funding. Money, especially recurrent funds under departmental control, is so often the limiter of developments that special attention needs to be given to this. Committee skills, preparation of administrative papers, lobbying and budgeting skills are all very relevant to psychiatry in Africa.

Psychiatrists in Africa are very active in teaching and are often involved in courses. Teaching techniques are therefore also relevant.

\section{Orientation}

Newly arrived trainees will have had little experience of assessing overdoses, dealing with neurosis and personality disorder, working in collaboration with a general practitioner, having a wide-range of drugs to choose from, having unstinted access to investigations, and legal safeguards to the rights of patients. All these should be explained as soon as possible to prevent later dissatisfaction on either side.

The emotional experience of a long visit to another country is a useful reminder of the pressures on a trainee from abroad simply by virtue of their being in a strange country and away from family and friends. My own experience is that there are some useful antidotes to the bewilderment and unease. Immersion in familiar work is one, and a clearly defined programme of duties is therefore particularly helpful in the early stages. Filling the evenings and weekends is also important for morale. There is no short-cut to this but living in the hospital, having contact with another trainee from one's country (who may or may not speak your first language), and organised social events may all be valuable.

Most trainees are happy to tolerate the inconvenience of travel for the sake of training, and there is a tendency for many to want all the training that is going. In Manchester, for example, most enrol for the MSc course as well as their other training. New opportunities breed new ambitions. It is another of the responsibilities of the clinical tutor to ensure that these do not also lead to new and unexpected disappointments.

\section{Acknowledgements}

I am grateful to the British Council for sponsoring my trip to Zambia, to Professor Haworth who invited me, to Drs Msoni, Mbatia, Wakil and Fikre who went out of their way to show me their countries' psychiatric services, to many people for hospitality, to the University of Manchester for study leave, and to Professor David Goldberg who kindly agreed to shoulder my clinical responsibilities in addition to his other burdens while I was away. Drs Mbatia and Eleni have kindly read and commented on the manuscript. Any errors or misunderstandings left in must, however, be counted my responsibility.

\title{
East-Anglian trainees' day
}

\author{
NeIl Hunt, Senior Registrar, St Bartholomew's Hospital, London EC1; Nigel Prior, \\ Registrar, Friern Hospital, London N11 3BP; and CHRISTINE VIZE, Registrar, \\ Fulbourn Hospital, Cambridge CB1 5EF
}

The East-Anglian CTC Trainees' Day was held at Friern Hospital, London, on 14 December 1989. The programme comprised a morning session with two speakers and lunch sponsored by Duphar, followed 
by an open forum on CTC training issues and an address by the final speaker. Approximately 30 trainees attended, mostly SHOs and registrars. Professor A. Wakeling, chairman of the East-Anglian Division of the Royal College, was present and took the opportunity to meet trainees from the region.

The opening address was delivered by Dr Greg Wilkinson, assistant editor of the British Journal of Psychiatry. Entitled 'Get That Paper Published', his talk drew on his experiences not only as an editor but as an author of psychiatric papers. Dr Wilkinson covered everything from the germination of an idea, the organisation and writing of the actual paper to the behind the scenes manœuvring sometimes required to see your paper in print. His humorous and informative account made the task of publishing seem much less daunting.

Professor Andrew Sims, Dean of the Royal College of Psychiatrists, was second speaker of the morning and talked on the broad topic of 'Educating Today's Psychiatrists'. An historical perspective of the development of the Royal College and its curriculum set the background for discussion relating to current changes to the Membership. Professor Sims reaffirmed the College's commitment to maintaining high standards of training nationally through the accreditation process. Furthermore, he highlighted the importance of research and of management skills for tomorrow's consultant psychiatrist. Future developments in education concern not only trainees but clinical tutors and examiners, who will also be given the opportunity to enhance their teaching and assessment skills.

An informal open forum was chaired by the CTC representatives after lunch. Issues of importance to trainees such as the implications of Achieving $a$ Balance, women in psychiatry, and the difficulties associated with part-time training were raised. This opportunity was also taken to explain the role of the CTC and its relevance to trainees.

The final speaker of the day was Mr Louis Blom-Cooper, Chairman of the Mental Health Act Commission, who addressed the meeting on the development, role and future functions of the Commission. Mr Blom-Cooper discussed the need for a good working relationship between the Commission and psychiatrists and confirmed that this was high on the Commission's agenda. His detailed address helped to illuminate the functions of this organisation.

Overall, the trainees' day was a success, providing an opportunity to meet colleagues from different parts of the region and to air views and concerns, which were remarkably homogeneous. However, the numbers attending were disappointingly low and this was attributed to Seasonal Attendance Disorder. A summertime meeting is proposed for next year.

\section{All Birmingham rotational scheme for training in psychiatry (1984-1989)}

\section{Some implications for Achieving a Balance* (Personal view)}

\section{Martin H. Davies Consultant Psychiatrist, The Midland Nerve Hospital, Edgbaston, Birmingham B15 2NJ}

This very large training scheme was formed at the suggestion of the then newly appointed Professor of

\footnotetext{
* Originally presented as a contribution to the Psychiatric Tutors Conference, University of York 28-30 September 1989: 'Training Psychiatrists for the 1990s'.
}

Psychiatry, Ian Brockington, who saw that in the existing rotations the balance between specialty and general posts was very uneven. He also argued convincingly that it would attract more trainees of high calibre and improve the morale and enthusiasm for training of the consultants, particularly in those 